\title{
Using Chlorophyll Fluorescence Imaging for Early Assessment of Photosynthesis Tolerance to Drought, Heat and High Illumination
}

\author{
María José Quiles, Helena Ibáñez and Romualdo Muñoz \\ Department of Plant Biology, Faculty of Biology, University of Murcia, Murcia \\ Spain
}

\section{Introduction}

Plants are frequently exposed to environmental stress both in natural and agricultural conditions and it is common for more than one abiotic stress to occur at a given time; for example, drought, heat and high illumination. The concept of stress is intimately associated with that of stress tolerance, which is the plant's ability to cope with an unfavourable environment. Plants exhibit great variations in their tolerance to stress. Some plants show sufficient developmental plasticity to respond to a range of light regimes, growing as sun plants in sunny areas and as shade plants in shady habitats. However, other species of plants are adapted to sunny environments or to shaded environments, and they show different levels of tolerance to high illumination. Generally, sun plants support exposure to high light better than shade plants, which experience photoinhibition (Bray et al., 2000; Levitt, 1980; Osmond, 1994; Saura \& Quiles, 2008; Wentworth et al., 2006).

Abiotic stress limits crop productivity and plays a major role in determining the distribution of plant species across different types of environments. Thus, understanding the physiological processes that underlie stress injury and the tolerance mechanisms of plants to environmental stress is of immense importance for both agriculture and the environment. Tolerance to environmental stresses results from integrated events occurring at all organization levels, from the anatomical and morphological to the cellular, biochemical and molecular level. At the biochemical level, plants alter their metabolism in various ways to accommodate environmental stress, with photosynthesis being the most important of these ways.

The photosynthetic apparatus in the plants absorbs large amounts of light energy and processes it into chemical energy. The absorption of photons excites the pigment molecules and this excitation energy is used in the photochemical reactions of photosynthesis, though part of the excitation energy is dissipated by fluorescence (emission of photons by chlorophyll molecules) and heat emission, principally in the antenna system. These three processes (photochemistry, fluorescence and thermal energy dissipation) compete in the dissipation of the excitation energy, while the total energy dissipated is the sum of all three (Long et al., 1994). Estimation of these processes in different conditions will permit us 
compare the competition that exists among the three of them and to evaluate possible alterations in the functioning of the photosynthetic apparatus. When plants are exposed for long periods of time to more light than they can use, photosynthesis is inhibited in a phenomenon known as photoinhibition. If the excess of absorbed light energy is not dissipated safely toxic species may be produced which can damage the photosynthetic apparatus. Photosynthetic organisms therefore contain a complex set of regulatory and repair mechanisms to avoid this situation. However, even with all these protective mechanisms, the photosynthetic apparatus is still sometimes damaged. PS II is the most sensitive site to photoinhibition, whereas PS I is more stable, probably because it plays a photoprotective role through cyclic electron flow (Quiles and López, 2004). In high-light conditions, the xanthophylls cycle operates, of which violaxanthin together with antheraxanthin and zeaxanthin are components (Demmig-Adams \& Adams, 1993; Lichtenthaler et al., 1992; Schindler \& Lichtenthaler, 1994, 1996). The xanthophylls cycle is essential to prevent the rapid photoinhibition of PS II (Havaux \& Gruszecki, 1993; Lichtenthaler \& Babani, 2004; Ruban \& Horton, 1995). Sun plants accumulate zeaxanthin during high-light stress of several hours to photoprotect their photosynthetic apparatus against photoinhibition and photooxidation, whereas shade plants do not possess zeaxanthin but only its oxidized form violaxanthin with some traces of antheraxanthin, and these plants are more sensitive to photoinhibition (Lichtenthaler \& Babani, 2004 ).

The classic methods used to determine the damage induced by adverse factors in leaves (such as the measurement of transpiration, respiration and photosynthesis rates; stomatal conductance; water potential; the concentration of photosynthetic pigments, stress metabolites and heat shock proteins) are all quite slow and require considerable effort. Moreover, many of these methods only provide one datum per leaf and measurement, and involve the destruction of tissues, so that subsequent measurements are not possible in the same leaf. In many cases, these methods are effective only for assessing the damage caused by stress to the plant in advanced situations, when the damage is visible, but do not allow early detection of alterations caused by adverse conditions, before the damage becomes visible. This is unfortunate because early detection is important and, in many cases, would make it possible to prevent the onset of irreversible damages. For these reasons, it would be of great interest to develop rapid, non-destructive and quantitative techniques for the early detection of stress in plants. One non-intrusive method for monitoring photosynthetic events and for judging the physiological state of the plant is to measure the chlorophyll fluorescence emitted by intact plant leaves, using a fluorometer (Sayed, 2003). Based on pulse amplitude modulation (PAM) and the saturation pulse method (Schreiber, 2004), chlorophyll fluorometry provides quantitative information concerning the maximal quantum yield of PS II in dark-adapted leaves, the fluorescence yield, the effective PSII quantum yield or photochemical efficiency and the non-photochemic quenching of fluorescence, which represents the heat dissipation in the antenna system (Müller et al., 2001). Three major components of non-photochemical quenching have been identified in plants, namely, energy-dependent quenching, photoinhibitory quenching and statetransition quenching, which are related to trans-thylakoid proton gradient, photoinhibition and energy redistribution, respectively (Allen, 1992; Krause, 1988; Krause \& Weis, 1991).

The rate of fluorescence emission depends on the absorbed light flux and on all the competing reactions that result in a return of the excited chlorophyll molecule to the ground state. The most important of those reactions are the photochemical reactions, thermal deactivation and the excitation energy transfer. In the PS II reaction center, the primary 
photochemical reaction is the transfer of one electron from pigment $\mathrm{P}_{680}$ in the first excited singlet state $\left(\mathrm{P}_{680^{*}}\right)$ to pheophytin $a$. From there, the electron is transferred to the primary quinone-type acceptor, $\mathrm{Q}_{\mathrm{A}}$. When all the reaction centers are in an active state, with the quinones totally or partially oxidized ("open" state), the fluorescence yield is minimal $\left(\mathrm{F}_{0}\right)$. However, when $\mathrm{Q}_{\mathrm{A}}$ is fully reduced, the excitation of $\mathrm{P}_{680}$ cannot result in stable charge separation and all the reaction centers are in a "closed" state; in this situation, maximum fluorescence yield $\left(\mathrm{F}_{\mathrm{M}}\right)$ is obtained. The variable fluorescence emission $\left(\mathrm{F}_{\mathrm{V}}\right)$, is the difference between $F_{M}$ and $F_{0}\left(F_{V}=F_{M}-F_{0}\right)$. In a dark-adapted leaf, the plastoquinone pool is fully oxidized, the reaction centers are open and the fluorescence emitted under a weak measuring light is minimal $\left(\mathrm{F}_{0}\right)$. When a saturating pulse of white light is given the plastoquinone pool is reduced, the rate of $Q_{A}$ reduction being faster than the rate of reoxidation, the reaction centers are closed and $F_{M}$ is reached; at that moment the maximal quantum yield of PS II can be estimated as $\mathrm{F}_{\mathrm{V}} / \mathrm{F}_{\mathrm{M}}$. This ratio is an important and easily measurable parameter of the physiological state of the photosynthetic apparatus in intact plant leaves. Additionally, the kinetic of the increase in fluorescence during the saturation pulse can be displayed as the fluorescence induction curve. Most fluorescence is emitted by the PS II antenna, and PS I only contributes around 1-2 \% of the total fluorescence; for this reason, the changes in this radiation reflect the state of PS II (Krause and Weis, 1991).

In recent years, the versatility of the chlorophyll fluorescence measurement technique has increased significantly with the development of fluorescence imaging systems, these provides a powerful tool for investigating leaf photosynthesis in a variety of conditions and reveal a wide range of internal leaf characteristics, including spatial variations due to differences in physiology and development (for a review see Papageorgiou \& Govindjee, 2004). This technique may also represent a simple and effective tool for the early detection of the effects caused by adverse factors (Oxborough, 2004a), which affect photosynthesis and cause an imbalance in the processes of excitation energy dissipation. Fluorescence imaging permits us to compare the variation in these processes and to study any damage caused in the same leaf as time progresses. However, not all fluorescence parameters are suitable for the early detection of plant stress. Usually, changes in the maximum quantum yield of PS II are used as an indicator of the functional state of the photosynthetic apparatus (Barbagallo et al., 2003; Oxborough, 2004b), since this parameter, which has a value between 0.70 and 0.85 in unstressed leaves, falls under the influence of adverse factors (Ehlert \& Hincha, 2008; Havaux \& Lannoye, 1985; Joshi \& Mohantly, 2004; Quiles \& López, 2004; Teicher et al., 2000). However, in the present paper we show that in both sun (Chrysanthemum morifolium) and shade (Spathiphyllum wallisii) plants exposed to drought, high illumination and heat and showing no visible damage, the images of the maximal quantum yield of PS II $\left(\mathrm{F}_{\mathrm{v}} / \mathrm{F}_{\mathrm{m}}\right)$ in dark-adapted leaves vary little from those in control plants, and, in all cases, the values are quite normal (above 0.74). Therefore, other fluorescence parameters are required to assess the tolerance of plants to those adverse factors. In this respect, we show that images of fluorescence yield, the effective PSII quantum yield and the non-photochemical quenching of fluorescence in illuminated leaves clearly showed variations in the energy dissipation processes between sun and shade plants exposed to drought, high illumination and heat. As a consequence, the measurement of these fluorescence parameters can be considered a better and earlier indicator of functional alterations of the photosynthetic apparatus than maximal quantum yield of PS II $\left(\mathrm{F}_{\mathrm{v}} / \mathrm{F}_{\mathrm{m}}\right)$, which, as we have mentioned, shows only small variations in response to these adverse conditions. 


\section{Materials and methods}

\subsection{Plant material and growth conditions}

Chrysanthemum morifolium (sun plant) and Spathiphyllum wallisii (shade plant) were grown in $500 \mathrm{~mL}$ pots at $22-25{ }^{\circ} \mathrm{C}$ in the greenhouse with a natural photoperiod, under daytime irradiation maxima of around 800 and $200 \mu \mathrm{mol} \mathrm{m} \mathrm{m}^{-2} \mathrm{~s}^{-1}$ PPFD (sun and shade plants, respectively) and controlled watering to avoid drought stress (control conditions). To simulate stress conditions, adult plants were transferred to cultivation chambers and exposed to $18 \mathrm{~h}$ photoperiods of high light intensity $\left(1060 \mu \mathrm{mol} \mathrm{m}^{-2} \cdot \mathrm{s}^{-1} \mathrm{PPFD}\right)$ supplied by a $100 \mathrm{~W}$ Flood Osram (Augsburg, Germany) white light lamp, at $35^{\circ} \mathrm{C}$, followed by $6 \mathrm{~h}$ nightperiods at $24{ }^{\circ} \mathrm{C}$, decreasing the irrigation to $50 \mathrm{~mL} /$ day, which was applied after the start the night period.

\subsection{Plant water status and pigments measurements}

Plant water status was estimated by measuring the relative water content of leaves (RWC). The leaves were collected and immediately weighed to determine fresh weight (FW). They were then re-hydrated for $24 \mathrm{~h}$ at $4{ }^{\circ} \mathrm{C}$ in darkness to determine the turgid weight (TW), and subsequently oven-dried for $24 \mathrm{~h}$ at $85^{\circ} \mathrm{C}$ to determine the dry weight (DW). The RWC was determined as $100 \times(\mathrm{FW}-\mathrm{DW}) /(\mathrm{TW}-\mathrm{DW})$.

Total Chlorophyll and carotenoids were determined by Lichtenthaler \& Wellburn's method using $80 \%(\mathrm{v} / \mathrm{v})$ acetone as solvent.

\subsection{Chlorophyll fluorescence measurements}

Chlorophyll fluorescence was imaged, using the MINI-version of the Imaging-PAM (Heinz Walz GmbH, Effeltrich, Germany), in selected leaves attached to plants for the control and stress conditions and the measurements were made after the last night-period. The fluorometer used employs the same blue LEDs for the pulse modulated measuring light, continuous actinic illumination and saturation pulses. The minimal fluorescence yield $\left(\mathrm{F}_{0}\right)$ and the maximal fluorescence yield $\left(\mathrm{F}_{\mathrm{m}}\right)$, were measured in dark-adapted samples. $\mathrm{F}_{0}$ was measured at a low frequency of pulse modulated measuring light, while $\mathrm{F}_{\mathrm{m}}$ was measured with the help of a saturation pulse. The maximal quantum yield of PS II was calculated as $\mathrm{F}_{\mathrm{v}} / \mathrm{F}_{\mathrm{m}}=\left(\mathrm{F}_{\mathrm{m}}-\mathrm{F}_{0}\right) / \mathrm{F}_{\mathrm{m}}$.

Light response curves were realised illuminating the selected leaves with actinic light of different intensities $\left(20,41,76,134,205,249,300,371,456,581,726 \mu \mathrm{mol} \mathrm{m} \mathrm{m}^{-2} \cdot \mathrm{s}^{-1}\right.$ PPFD), with 2 min illumination periods at each intensity. After each illumination periods a saturation pulse was applied to determine the relative electron transport rate, the effective PS II quantum yield of illuminated samples $\left(\left(\mathrm{F}_{\mathrm{m}}{ }^{\prime}-\mathrm{F}\right) / \mathrm{F}_{\mathrm{m}}{ }^{\prime}\right)$ and non-photochemical quenching $(\mathrm{Nq})$ ), all of which were automatically calculated by the ImagingWin software. Results are shown as color-coded images of the maximal quantum yield of PS II $\left(\mathrm{F}_{\mathrm{v}} / \mathrm{F}_{\mathrm{m}}\right)$, the fluorescence yield (F), the effective PS II quantum yield of illuminated samples $\left(\left(F_{m}{ }^{\prime}-F\right) / F_{m}{ }^{\prime}\right)$ and non-photochemical quenching $(\mathrm{Nq})$ ).

\section{Results}

The relative water content (RWC) was measured in the leaves from Chrysanthemum morifolium and Spathiphyllum wallisii plants at the start the experiment (control) and immediately after exposure to each stress photoperiod (Figure 1). The RWC values 
decreased in both species to around $60 \%$ after the two stress photoperiods with low watering, indicating that the plants were subjected to moderate water deficit.

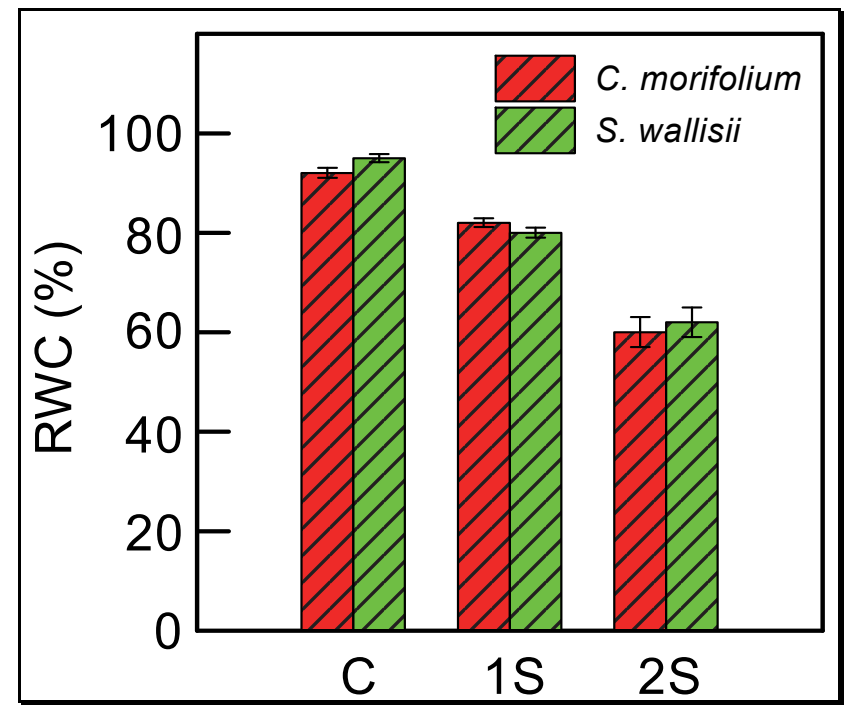

Fig. 1. The relative water content (RWC) of leaves from Chrysanthemum morifolium and Spathiphyllum wallisii plants in control conditions (C) and after exposure to one (1S) and two (2S) stress photoperiods ( $18 \mathrm{~h}, 1060 \mu \mathrm{mol} \mathrm{m}^{-2} \cdot \mathrm{s}^{-1} \mathrm{PPFD}, 35^{\circ} \mathrm{C}$ and low watering). The stress photoperiods were separated by $6 \mathrm{~h}$ night-periods at $24^{\circ} \mathrm{C}$. The values are means $\pm \mathrm{SE}$ from four independent experiments.

The fluorescence imaging technique was used to assess photosynthesis in sun and shade plants. Figure 2 shows the images of the maximal quantum yield of PS II $\left(F_{v} / F_{m}\right)$ from a typical leaf, and the means values $\pm \mathrm{SE}$ of $C$. morifolium and $S$. wallisii plants in control conditions and exposed to one and two stress photoperiods. The results are shown as colour-coded images according to the pattern shown below the images. All the leaves provided similar images with a homogeneous colour throughout the leaf. The mean $F_{v} / F_{m}$ values in all cases were higher than 0.74 , indicating that maximal quantum yield of PS II in leaves from C. morifolium and S. wallisii plants, in control conditions and exposed to one and two stress photoperiods, was quite normal (Krause \& Weis, 1991; Schereiber et al., 1997) and that the maximal photosynthetic capacity of PS II in these species was probably unaffected by the stress condition used here; furthermore it seems that the photosynthetic apparatus is protected by mechanisms that dissipate excess excitation energy.

Figure 3 shows the amounts of total chlorophylls and carotenoids in leaves from $C$. morifolium and S. wallisii plants in control conditions and exposed to one and two stress photoperiods. No significant difference was observed between the control plants and those exposed to stress photoperiods in either sun or shade plants. 


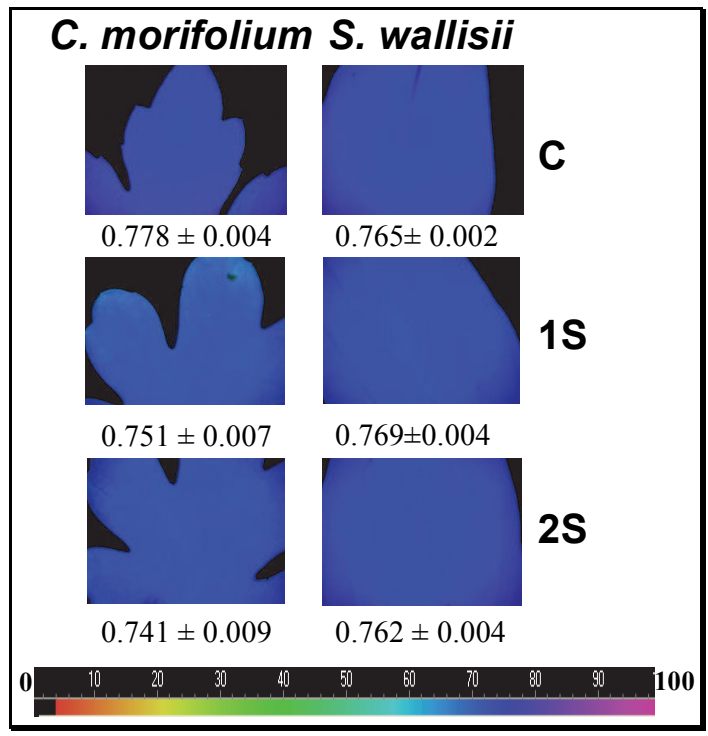

Fig. 2. Images and values of the maximal quantum yield of PS II $\left(\mathrm{F}_{\mathrm{v}} / \mathrm{F}_{\mathrm{m}}\right)$ from typical leaves of Chrysanthemum morifolium and Spathiphyllum wallisii plants in control conditions (C) and exposed to one (1S) and two (2S) stress photoperiods $\left(18 \mathrm{~h}, 1060 \mu \mathrm{mol} \mathrm{m} \mathrm{m}^{-2} \cdot \mathrm{s}^{-1} \mathrm{PPFD}, 35^{\circ} \mathrm{C}\right.$ and low watering). The stress photoperiods were separated by $6 \mathrm{~h}$ night-periods at $24^{\circ} \mathrm{C}$. Images are colour coded according to the pattern ( 0 to $1 \times 100$ range) shown below the images. The figure shows representative images from four independent experiments and the values are means $\pm \mathrm{SE}$ from four different entire leaves.

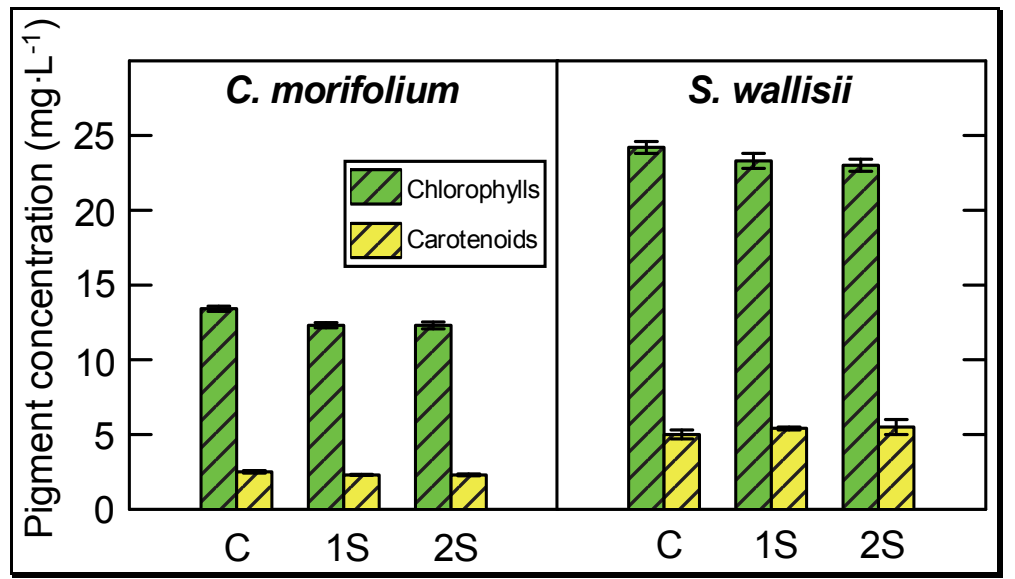

Fig. 3. Total chlorophyll and carotenoids of leaves from Chrysanthemum morifolium and Spathiphyllum wallisii plants in control conditions (C) and exposed to one (1S) and two (2S) stress photoperiods ( $18 \mathrm{~h}, 1060 \mu \mathrm{mol} \mathrm{m} \mathrm{m}^{-2} \cdot \mathrm{s}^{-1} \mathrm{PPFD}, 35^{\circ} \mathrm{C}$ and low watering). The stress photoperiods were separated by $6 \mathrm{~h}$ night-periods at $24^{\circ} \mathrm{C}$. The values are means $\pm \mathrm{SE}$ from four independent experiments. 
Figure 4 shows the light response curves for the relative electron transport rate in leaves from C. morifolium and S. wallisii plants in control conditions and exposed to one and two stress photoperiods. In both species, when light was not excessive, the relationship between the relative electron transport rate and the light intensity was linear (optimum line, Fig. 4). When the light became excessive, the relative electron transport rate decreased below the values predicted by the optimum line. Finally, when the photonic flux density was increased, a satured rate was reached, which represents the capacity of photosynthetic electron transport (Schreiber et al., 1997). In low light intensity of less than $100 \mu \mathrm{mol} \mathrm{m} \mathrm{m}^{-2} \cdot \mathrm{s}^{-1}$, the relative electron transport rate was similar in control and stress-exposed C. morifolium plants, but not in $S$. wallisii, where the values in plants exposed to stress photoperiods were lower than those predicted by the optimum line. the capacity of photosynthetic electron transport was greater in C. morifolium than in S. wallisii control plants and decreased in the plants of both species exposed to stress photoperiods.

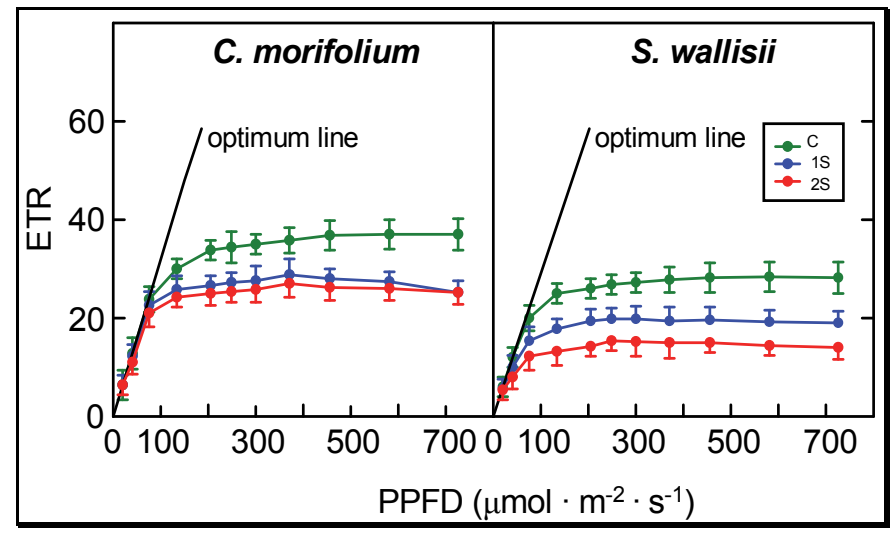

Fig. 4. Light response curves for the relative electron transport rate (ETR) in intact darkadapted leaves of Chrysanthemum morifolium and Spathiphyllum wallisii plants in control conditions (green graphics) and exposed to one (blue graphics) and two (red graphics) stress photoperiods ( $18 \mathrm{~h}, 1060 \mu \mathrm{mol} \mathrm{m} \mathrm{m}^{-2} \cdot \mathrm{s}^{-1} \mathrm{PPFD}, 35^{\circ} \mathrm{C}$ and low watering). The stress photoperiods were separated by $6 \mathrm{~h}$ night-periods at $24^{\circ} \mathrm{C}$. The values are means $\pm \mathrm{SE}$ from six independent experiments.

Figure 5 shows the images obtained at two light intensities (20 and $300 \mu \mathrm{mol} \mathrm{m} \mathrm{m}^{-2} \mathrm{~s}^{-1}$ ) of the effective PS II quantum yield (Y(II)), the fluorescence yield (F) and non-photochemical quenching $(\mathrm{Nq})$ ) from a typical leaf of $C$. morifolium and S. wallisii plants in control conditions and exposed to one and two stress photoperiods. For comparison purposes, the data from the analysed entire leaves were also averaged and the medium values $\pm S E$ are shown in the histograms.

Leaves from the control plants and those exposed to stress photoperiods showed changes in the images of the fluorescence parameters in both sun and shade species illuminated with low and high light intensity. With low illumination $\left(20 \mu \mathrm{mol} \mathrm{m} \mathrm{m}^{-2} \mathrm{~s}^{-1}\right)$ the photochemical efficiency of control plants was approximately 0.5 and the leaves provided Y(II) images of a green-blue colour in both species; the fluorescence emission of control plants was higher in sun (0.32) than in shade species $(0.21)$, while $\mathrm{Nq}$ was lower in sun plants $(0.16$, yellow 


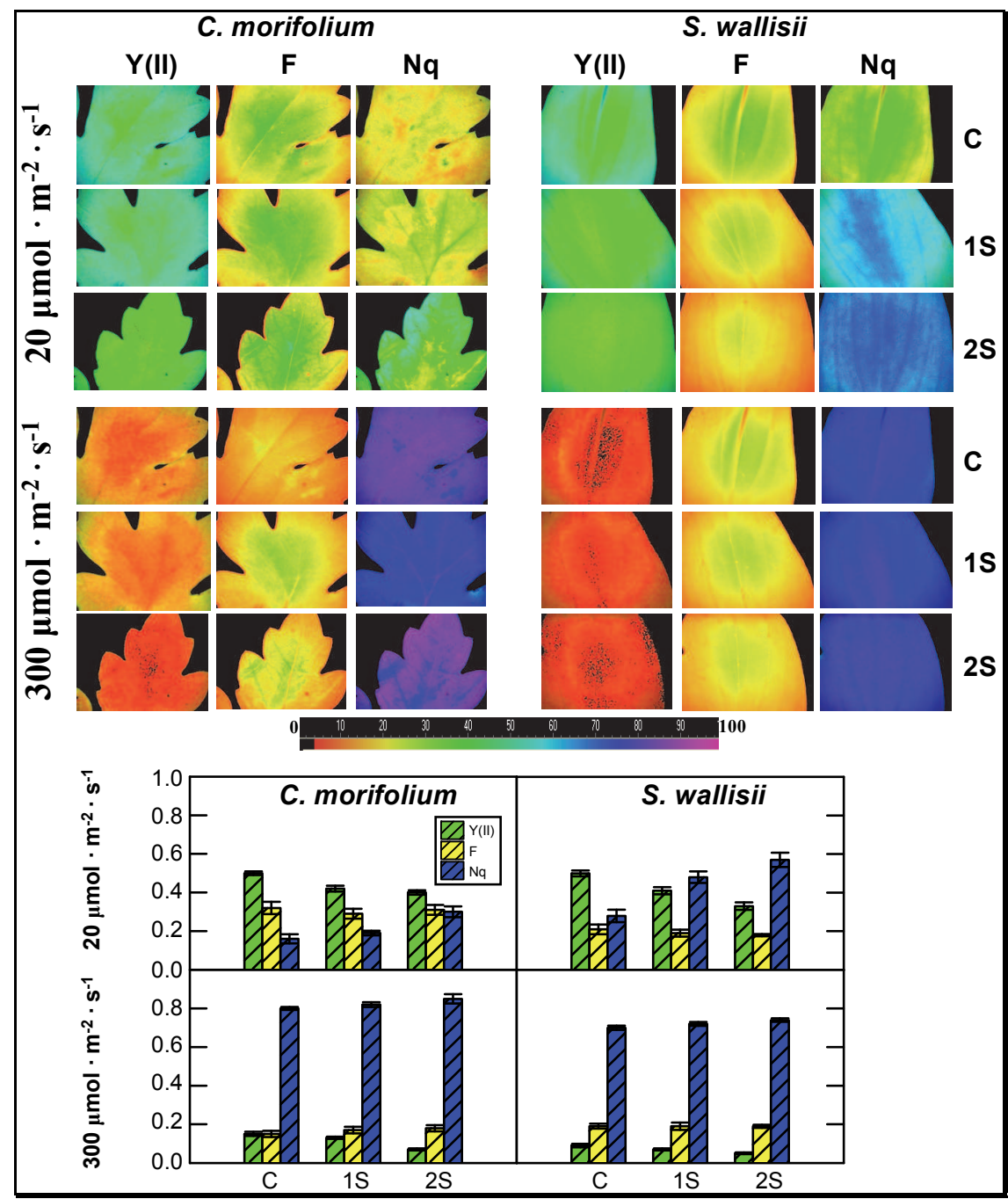

Fig. 5. Images at 20 and $300 \mu \mathrm{mol} \mathrm{m}^{-2} \cdot \mathrm{s}^{-1}$ PPFD of the effective PS II quantum yield (Y(II)), the fluorescence yield $(\mathrm{F})$ and non-photochemical quenching $(\mathrm{Nq})$ from a typical leaf attached to Chrysanthemum morifolium and Spathiphyllum wallisii plants, in control conditions (C) and exposed to one (1S) and two (2S) stress photoperiods (18 h, $1060 \mu \mathrm{mol} \mathrm{m}^{-2} \cdot \mathrm{s}^{-1} \mathrm{PPFD}$, $35^{\circ} \mathrm{C}$ and low watering). The stress photoperiods were separated by $6 \mathrm{~h}$ night-periods at 24 ${ }^{\circ} \mathrm{C}$. Images are colour coded according to the pattern ( 0 to $1 \times 100$ range) shown below the images. The histograms show the means \pm SE of parameters calculated from variable chlorophyll fluorescence measurements in six entire leaves.

images) than in shade plants (0.28, green images). After one and two stress photoperiods, the effective PSII quantum yield and the fluorescence emission decreased, moreso in shade than in sun plants, while $\mathrm{Nq}$ increased, moreso in shade (blue images) than in sun plants 
(yellow-green images). When the same leaves were illuminated with $300 \mu \mathrm{mol} \mathrm{m}^{-2} \cdot \mathrm{s}^{-1}$, the Y (II) decreased in both species, although values were higher in sun than in shade species, and the C. morifolium images showed orange-red colour in control leaves, which changed to red after two stress photoperiods, while $S$. wallisii images showed red colour in all cases.

The $\mathrm{F}$ emission decreased in sun plants and the images showed orange and orange-green colours, whereas in shade plants the F emission decreased in leaves of the control plants, but after stress photoperiods the leaf images showed only slight differences from those illuminated with $20 \mu \mathrm{mol} \mathrm{m} \mathrm{m}^{-2} \mathrm{~s}^{-1}$. The $\mathrm{Nq}$ increased significantly in both species, although the values were higher in sun than in shade species.

\section{Discussion}

Fluorescence imaging represents a simple and non-invasive tool for the early detection of effects caused by adverse factors, which affect photosynthesis causing an imbalance in the processes of excitation energy dissipation (Long et al., 1994). This technique permits us to compare, by means of imagines, the variation in these processes and to study any damage caused in the same leaf as time progresses. Usually, changes in $F_{v} / F_{m}$ of leaves adapted to dark, which represents the maximal quantum yield of PS II (Krause \& Weis, 1991), are used as an indicator of the functional state of the photosynthetic apparatus (Barbagallo et al., 2003; Krause \& Jahns, 2004; Oxborough, 2004b), since this parameter, which has a value of between 0.70 and 0.85 in unstressed leaves, falls under the influence of adverse factors (Ehlert \& Hincha, 2008; Havaux \& Lannoye, 1985; Joshi \& Mohantly, 2004; Quiles \& López, 2004; Teicher et al., 2000).

Sun plants (C. morifolium) and shade plants (S. wallisii) were exposed to photoperiods with low watering, high illumination and heat. Even after two stress photoperiods no visible damage was observed in either plant species (not shown). Neither did the concentration of photosynthetic pigments or the $F_{v} / F_{m}$ values show any significant decrease after the stress photoperiods, suggesting that chloroplasts are protected by mechanisms that dissipate excess excitation energy to prevent damage to the photosynthetic apparatus under adverse conditions. In this respect, we have reported that chlororespiration and cyclic electron flow pathways are involved in the tolerance to adverse factors in both sun and shade species (Díaz et al., 2007; Gamboa et al., 2009; Ibañez et al., 2010; Quiles, 2006; Tallón \& Quiles, 2007). However, when the light response curves for the relative electron transport rate were depicted, differences were observed between control plants and those exposed to stress photoperiods, the capacity of photosynthetic electron transport being lower in plants exposed to stress photoperiods in both species. In C. morifolium after one or two stress photoperiods, the values were similar and the capacity of photosynthetic electron transport was approximately $22 \%$ lower than in control plants. However, in S. wallisii differences between plants exposed to one and two stress photoperiods were observed and the capacity of photosynthetic electron transport after one and two stress photoperiods was approximately 27 and $44 \%$, respectively, lower than that of control plants.

The images of the fluorescence yield, the effective PS II quantum yield or photochemical efficiency and the non-photochemic quenching of fluorescence, which represents the heat dissipation in the antenna system (Müller et al., 2001), also showed significant differences, indicating that plants exposed to stress photoperiods behaved differently as regards the processes of dissipation of excitation energy, in each species. At low illumination (20 $\mu \mathrm{mol} \mathrm{m}^{-2} \cdot \mathrm{s}^{-1}$ ), fluorescence emission predominates over heat dissipation in the sun species, while the contrary occurs in the shade species, heat dissipation predominates over 
fluorescence emission. However, at high illumination $\left(300 \mu \mathrm{mol} \mathrm{m} \mathrm{m}^{-2} \mathrm{~s}^{-1}\right)$, when the photochemical efficiency significantly decreased because of the light saturation, the sun species was more efficient in dissipating excess energy in the form of heat.

\section{Conclusions}

We conclude that fluorescence imaging is a useful method for the early assessment of photosynthesis tolerance to adverse conditions, such as drought, high light and heat, when there is still no visible damage to plants. However, not all fluorescence parameters are effective, and analysis of the maximum quantum yield in leaves adapted to darkness was unable to detect significant differences between control plants and plants exposed to stress photoperiods. In contrast, the analysis in illuminated leaves of the relative electron transport rate and the fluorescence parameters, $\mathrm{Y}(\mathrm{II}), \mathrm{F}$ and $\mathrm{Nq}$, which are representative of the three processes of excitation energy dissipation (photochemistry, fluorescence and thermal dissipation, respectively) showed significant differences in the two species studied, indicating that sun species (C. morifolium) had greater tolerance to drought, heat and high illumination than the shade species (S. wallisii).

\section{Acknowledgment}

This work was supported by the Spanish Ministry of Science and Innovation (grant BFU2008-00331).

\section{List of abbreviations}

DW, dry weight;

F, fluorescence yield;

$\mathrm{F}_{\mathrm{m}}$, maximal fluorescence yield in the dark adapted state;

$\mathrm{F}_{0}$, minimal fluorescence yield in the dark adapted state;

$\mathrm{F}_{\mathrm{m}}^{\prime}$, maximal fluorescence yield in the light adapted state;

$\mathrm{F}_{\mathrm{v}}$, variable fluorescence;

FW, fresh weight;

LED, light-emitting diode;

$\mathrm{Nq}$, non-photochemical quenching;

PAM, pulse amplitude modulation;

PPFD, photosynthetic photon flux density;

PS, photosystem;

RWC, relative water content;

TW, turgid weight;

Y(II), effective PS II quantum yield.

\section{References}

Allen, J.F. (1992). Protein phosphorylation in regulation of photosynthesis. Biochim Biophys Acta. 1098: 275-335.

Barbagallo, R.P.; Oxborough, K.; Pallet, K.E. \& Baker N.R. (2003). Rapid, non-invasive screening for perturbations of metabolism and plant growth using chlorophyll fluorescence imaging. Plant Physiol. 132:485-493. 
Bray, E.A.; Bailey-Serres, J. \& Weretilnyk, E. (2000). Responses to abiotic stresses. In Biochemistry and Molecular Biology of Plants, W. Buchanan, W. Gruissem \& R. Jones (Eds.), pp1158-1203. American Society of Plant Physiologists, ISBN 0-943088-37-2, Rockville, MD, USA.

Demmig-Adams, B. \& Adams, W.W. (1993). Photoprotection and other responses of plants to high light stress. Annu Rev Plant Physiol Plant Mol Biol 43: 599-626.

Díaz, M.; De Haro, V.; Muñoz, R. \& Quiles, M.J. (2007). Chlororespiration is involved in the adaptation of Brassica plants to heat and high light intensity. Pant Cell Environ 30:1578-1585.

Ehlert, B. \& Hincha K. (2008). Chlorophyll fluorescence imaging accurately quantifies freezing damage and cold acclimation responses in Arabidopsis leaves. Plant Methods 4:12 doi:10.1.186/1746-4811-4-12.

Gamboa, J., Muñoz, R. \& Quiles, M.J. (2009). Effects of antimycin A and n-propyl gallate on photosynthesis in sun and shade plants. Plant Sci 177:643-647.

Havaux, M. \& Gruszecki, W.I. (1993). Heat and light-induced Chl a fluorescence changes in potato leaves containing high or low levels of the carotenoid zeaxanthin, indicators of a regulatory effect of zeaxanthin on thylakoid membrane fluidity. Photochem Photobiol 58: 607-614.

Havaux, M. \& Lannoye, R. (1985). In vivo chlorophyll fluorescence and delayed light emissions as rapid screening techniques for stress tolerance in crop plants. $Z$. Pflanzenzucht. 95: 1-13.

Ibáñez, H.; Ballester, A.; Muñoz, R. \& Quiles, M.J. (2010). Chlororespiration and tolerance to drought, heat and high illumination. J Plant Physiol. 167:732-738.

Joshi, M.K. \& Mohanty, P. (2004). Chlorophyll $a$ fluorescence as a probe of heavy metal ion toxicity in plants. In: Chlorophyll a fluorescence. A signature of photosynthesis, G. Papageorgiou \& Govindjee Eds.), pp. 637-661. Springer, ISBN 1-4020-3217-X, Dordrecht. The Netherlands

Krause, G.H. (1988). Photoinhibition of photosynthesis. An evaluation of damaging and protective mechanisms. Physiol Plant. 74: 566-574.

Krause, G.H. \& Jahns, P. (2004). Non-photochemical energy dissipation determined by chlorophyll fluorescence quenching: characterization and function. In: Chlorophyll a fluorescence. A signature of photosynthesis, G. Papageorgiou \& Govindjee Eds.), pp. 463-495. Springer, ISBN 1-4020-3217-X, Dordrecht. The Netherlands.

Krause, G.H. \& Weis, E. (1991). Chlorophyll fluorescence and photosynthesis. The basics. Ann Rev Plant Physiol Plant Mol Biol 42: 313-349.

Levitt, J. (1980). Responses of plants to enviromental stresses, Vol. 1. Academic Press, ISBN 0124455018, New York, USA.

Lichtenthaler, H.K. \& Babani, F. (2004). Light adaptation and senescence of the photosynthetic apparatus. Changes in pigment composition, chlorophyll fluorescence parameters and photosynthetic activity. In: Chlorophyll a fluorescence. A signature of photosynthesis, G. Papageorgiou \& Govindjee Eds.), pp. 713-736. Springer, ISBN 1-4020-3217-X, Dordrecht. The Netherlands.

Lichtenthaler, H.K.; Burkart, S.; Schindler, C. \& Stober, F. (1992). Changes in photosynthetic pigments and in vivo chlorophyll fluorescence parameters under photoinhibitory growth conditions. Photosynthetica, 27: 343-353.

Lichtenthaler, H.K. \& Wellburn, A.R. (1983). Determinations of total carotenoids and chlorophylls $\mathrm{a}$ and $\mathrm{b}$ of leaf extracts in different solvents. Biochemical Society Transactions 11: 591-592. 
Long, S.P.; Humphries, S. \& Falkowski P.G. (1994). Photoinhibition of photosynthesis in nature. Ann Rev Plant Physiol Plant Mol Biol. 45: 633-662.

Müller, P.; Li, X.P. \& Niyogi, K.K. (2001). Non-photochemical quenching: a response to excess light energy. Plant Physiol. 125:1558-1566.

Osmond, C.B. (1994). What is photoinhibition? Some insights from comparisons of shade and sun plants. In: Photoinhibition of Photosynthesis: From Molecular Mechanisms to the Field. N.R. Baker \& J.R.Bowyer (Eds.), pp. 1-24. BIOS Scientific Publishers, ISBN 1872748-03-1, Oxford. United Kingdom.

Oxborough, K. (2004a). Using chlorophyll a fluorescence imaging to monitor photosynthetic performance. In: Chlorophyll a fluorescence. A signature of photosynthesis, G. Papageorgiou \& Govindjee Eds.), pp. 409-428. Springer, ISBN 1-4020-3217-X, Dordrecht. The Netherlands.

Oxborough, K. (2004b). Imaging of chlorophyll a fluorescence: theoretical and practical aspects of an emerging technique for the monitoring of photosynthetic performance. J Exp Bot. 55:1195-1205.

Papageorgiou, G. \& Govindjee. (2004). Chlorophyll a fluorescence. A signature of photosynthesis. Springer, ISBN 1-4020-3217-X, Dordrecht. The Netherlands

Quiles, M.J. (2006). Stimulation of chlororespiration by heat and high light intensity in oat plants. Plant Cell Environ. 29:1463-1470.

Quiles, M.J. \& López N.I. (2004) Photoinhibition of photosystems I and II induced by exposure to high light intensity during oat plant growth. Effects on the chloroplast NADH dehydrogenase complex. Plant Sci. 166: 815-823.

Ruban, A.V. \& Horton, P. (1995). Regulation of non-photochemical quenching of chlorophyll fluorescence in plants. Aus J Plant Physiol. 22: 221-230.

Sayed, O.H. (2003). Chlorophyll fluorescence as a tool in cereal crop research. Photosynthetica, 41: 321-30.

Saura, P. \& Quiles, M.J. (2009). Assessment of Photosynthesis Tolerance to Herbicides, Heat and High Illumination by Fluorescence Imaging. Open Plant Sci J. 3: 7-13.

Schindler, C. \& Lichtenthaler, H.K. (1994). Is there a correlation between light-induced zeaxanthin accumulation and quenching of variable chlorophyll a fluorescence? Plant Physiol Bioch. 32: 813-823.

Schindler, C. \& Lichtenthaler, H.K. (1996). Photosynthetic CO2 assimilation, chlorophyll fluorescence and zeaxanthin accumulation in field-grown maple trees in the course of a sunny and cloudy day. J Plant Physiol. 148: 399-412.

Schreiber U. (2004). Pulse-Amplitude (PAM) fluorometry and saturation pulse method. In Chlorophyll a fluorescence. A signature of photosynthesis. Edited by Papageorgiou G, Govindjee. Dordrecht: Springer; 279-319.

Schreiber, U.; Gademann, R.; Ralph, P.J. \& Larkum, A.W.D. (1997). Assessment of photosynthetic performance of Prochloron in Lissoclinum patella in hospite by chlorophyll fluorescence measurements. Plant Cell Physiol. 38:945-951.

Tallón, C. \& Quiles, M.J. (2007). Acclimation to heat and high light intensity during the development of oat leaves increases the NADH DH complex and PTOX levels in chloroplasts. Plant Sci. 173: 438-445.

Teicher, H.B.; Moller, B.L. \& Scheller, H.V. (2000). Photoinhibition of photosystem I in fieldgrown barley (Hordeum vulgare L.): induction, recovery and acclimation. Photosynth Res. 64: 53-61.

Wentworth, M.; Murchie, E.H.; Gray, J.E.; Villegas, D. \& Pastenes, C. (2006) Differential adaptation of two varieties of common bean to abiotic stress. J Exp Bot. 57: 699-709. 


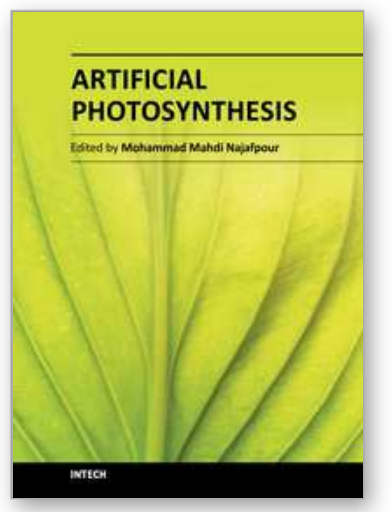

\author{
Artificial Photosynthesis \\ Edited by Dr Mohammad Najafpour
}

ISBN 978-953-307-966-0

Hard cover, 288 pages

Publisher InTech

Published online 24, February, 2012

Published in print edition February, 2012

Photosynthesis is one of the most important reactions on Earth, and it is a scientific field that is intrinsically interdisciplinary, with many research groups examining it. We could learn many strategies from photosynthesis and can apply these strategies in artificial photosynthesis. Artificial photosynthesis is a research field that attempts to replicate the natural process of photosynthesis. The goal of artificial photosynthesis is to use the energy of the sun to make different useful material or high-energy chemicals for energy production. This book is aimed at providing fundamental and applied aspects of artificial photosynthesis. In each section, important topics in the subject are discussed and reviewed by experts.

\title{
How to reference
}

In order to correctly reference this scholarly work, feel free to copy and paste the following:

María José Quiles, Helena Ibáñez and Romualdo Muñoz (2012). Using Chlorophyll Fluorescence Imaging for Early Assessment of Photosynthesis Tolerance to Drought, Heat and High Illumination, Artificial Photosynthesis, Dr Mohammad Najafpour (Ed.), ISBN: 978-953-307-966-0, InTech, Available from: http://www.intechopen.com/books/artificial-photosynthesis/using-chlorophyll-fluorescence-imaging-for-earlyassessment-of-photosynthesis-tolerance-to-drought-h

\section{INTECH}

open science | open minds

\section{InTech Europe}

University Campus STeP Ri Slavka Krautzeka 83/A 51000 Rijeka, Croatia Phone: +385 (51) 770447 Fax: +385 (51) 686166 www.intechopen.com

\author{
InTech China \\ Unit 405, Office Block, Hotel Equatorial Shanghai \\ No.65, Yan An Road (West), Shanghai, 200040, China \\ 中国上海市延安西路65号上海国际贵都大饭店办公楼405单元 \\ Phone: +86-21-62489820 \\ Fax: $+86-21-62489821$
}


(C) 2012 The Author(s). Licensee IntechOpen. This is an open access article distributed under the terms of the Creative Commons Attribution 3.0 License, which permits unrestricted use, distribution, and reproduction in any medium, provided the original work is properly cited. 